\title{
Research and Application of Safety Supervision Information Platform for Dangerous Chemicals in Port
}

\author{
Weiwei Ma ${ }^{1, a^{*}}$, Xiaoyan Dong ${ }^{1, b}$, Dong $\mathrm{Lu}^{1, \mathrm{c}}$ and $\mathrm{Li} \mathrm{Li}^{1, \mathrm{~d}}$ \\ ${ }^{1}$ China Waterborne Transport Research Institute, No.8, Xitucheng Road, Haidian District, Beijing, \\ P.R.China 100088 \\ amaww@wti.ac.cn, ${ }^{\text {b dongxy@wti.ac.cn, }{ }^{\mathrm{C} l u d o n g @ w t i . a c . c n, ~}{ }^{\mathrm{d}} \mathrm{lili} @ w t i . a c . c n}$
}

Keywords: Port; Hazardous chemicals; Safety supervision; 3D-GIS; Mobile Internet; Platform

\begin{abstract}
The safety supervision of hazardous chemicals in port is the most important task of China port safety supervision at present. Through analyzing the inadequacies and problems of port hazardous chemicals safety regulation in actual work, put forward the basic ideas of comprehensively improving the ability and level of port hazardous chemicals safety supervision by modern information technology such as video surveillance, 3D-GIS, Mobile Internet, virtual reality etc. And study framework, main functions and database structure of the hazardous chemicals safety supervision platform for port. Finally, introduce the main content and application of hazardous chemicals safety supervision platform for Dalian Port.
\end{abstract}

\section{Introduction}

At present, the number of dangerous goods terminal in China is increasing, and the scale of dangerous chemical storage tank and pipeline is always widening. According to statistics, there are a total of 9798 dangerous chemical storage tanks, capacity of about 96 million 230 thousand cubic meters, and 9169 pipelines more than $5900 \mathrm{~km}$, transport capacity of nearly 1 billion 200 million in 18 provinces. The security risks from the large number of hazardous chemicals storage tanks and pipelines are also growing with each passing day. In 2010, Dalian "7.16" petroleum oil pipeline explosion, 1500 tons of oil leaking into sea, pollutes more than 430 square kilometers of sea. The direct economic loss was 2.33 billion, besides 85.1 million rescue cost and 11.68 billion polluting costs. In 2013, "11.22" pipeline leak explosion accidents in Qingdao, caused 62 persons death, 136 persons were injured. Two years later, Dangerous goods warehouse explosion in Tianjin, killed 165 persons, with the loss of 68.66 million[1]. Therefore, the accidents of hazardous chemicals in port is great harm, affecting wide range, dealing with difficult, which brings serious test and puts forward higher requirements on safety supervision for port.

Some regulations, such as Dangerous Chemical Safety Management Regulations (State Council Decree No. 591) and Port Dangerous Goods Safety Management Regulation (Ministry of transport that [2012] in No. 9) has clearly stipulated safety supervision department of dangerous chemical storage tanks and pipelines is the administrative department of port. According to research, part of the administrative department of port has carried out information construction for hazardous chemicals safety at present, to strengthen the dynamic control of port dangerous chemical information, improve the capacity of hazardous chemicals safety supervision. But there are many problems in this work.

First, hazardous chemicals safety supervision in port still rely on artificial supervision, but lack of corresponding supervision facilities, and supervision ways and means. Supervision information level is low, lack of thinking and skills to complete port hazardous chemicals safety supervision[2,3].

Second, the administrative department of port is short to summarizing dangerous chemical safety monitoring data, lead to lacking dynamic data. And also lack of data analysis means such as electronic map, down to lacking technical support through information system when emergency commanding.

Third, is more important, a lot of emergency command systems can been used in the early time, but due to the lack of combination with the daily safety supervision, the disconnection of peacetime 
and wartime results in emergency command system database information could not be updated timely. When accident happened, these systems can't to make effective decision and become cosmetic[4].

Based on the above problems, propose construction scheme of hazardous chemicals safety supervision platform based on the idea of combination of peacetime and wartime. Connect hazardous chemicals daily safety supervision, emergency preparedness exercises, and command scheduling, and integrate the behind data resources. Provide overall solution for port hazardous chemicals safety supervision information work[5,6,7].

\section{Platform Goals}

In view of the problems and deficiencies in the current safety supervision of hazardous chemicals in port, set the overall goal of the hazardous chemicals safety supervision platform.

First, establish hazardous chemicals geographic information system for port based on 3D visualization. By high resolution remote sensing data, establish visualization" electronic distribution map database for hazardous chemicals business, terminals, tank farms, pipeline and facilities of safety and emergency.

Second, establish hazardous chemicals emergency aided decision system for port based on the linkage of 2D and 3D. based on electronic distribution map, in order to realize better visual analysis, establish realize the hazardous chemicals emergency aided decision system, covering from accident alarm, scene analysis, emergency rescue command, forming the complexion which supports clear level, rapid joint operation, effective command.

Third, establish hazardous chemicals daily safety management system for port based on Mobile Internet. Through the daily management of port hazardous chemicals, the responsibilities of port hazardous chemicals safety supervision is to integrating information of major hazard source identification and filing, port enterprise security management and standardized management, security assessment record, daily supervision and inspection.

At the same time, in order to make better use of the above systems, the administrative department of port can establish of port hazardous chemicals emergency command center, the corresponding configuration of the remote monitoring equipment, regulatory testing equipment, field evidence equipment, regulatory tools, emergency communication tools and so on, according to the actual need.

\section{Platform Architecture Design}

According to the actual demand and the construction goal of hazardous chemicals safety supervision in port, this paper designs the overall architecture of hazardous chemicals safety supervision platform for port, as shown as Fig.1.

Network platform layer is basic conditions to carry the data transmission and exchange, generally relying on government outer net to realize information acquisition, integration, processing, analysis and display. Network layer provides support services for the data resource layer, business application layer, etc. in the network transmission.

Emergency command center includes the decoration design of emergency command center command hall, emergency consultation room, conference room, news release room, emergency command center, emergency consultation room. And systems design of mechanical and electrical system. Mobile emergency command platform is the extension and expansion of the emergency command and dispatching platform.

Basic support systems include the acquisition and integration port business integrated data, the integration of video data, call center system, 2D/3D GIS platform. The basic support layer provides software and hardware support for the application system [8].

Data resource layer exists by integration and exchange of the data in the existing business system. By the unified construction standards and data exchange standard, to ensure that the information resources successfully exchange in the collection, processing, transmission and analysis, management and sharing of the whole process in the system, in order to achieve knowledge 
management and decision support. Data resource layer provides the data support for the application and development of all kinds of application systems.

Application layer, based on basic support systems and data resource layer, in-depth analyzes the demand port hazardous chemicals safety supervision based on the idea of combination of peacetime and wartime, integrates and designs business application system, including hazardous chemicals geographic information system for port based on 3D visualization, hazardous chemicals emergency aided decision system for port based on the linkage of 2D and 3D, and hazardous chemicals daily safety management system for port based on Mobile Internet[9,10].

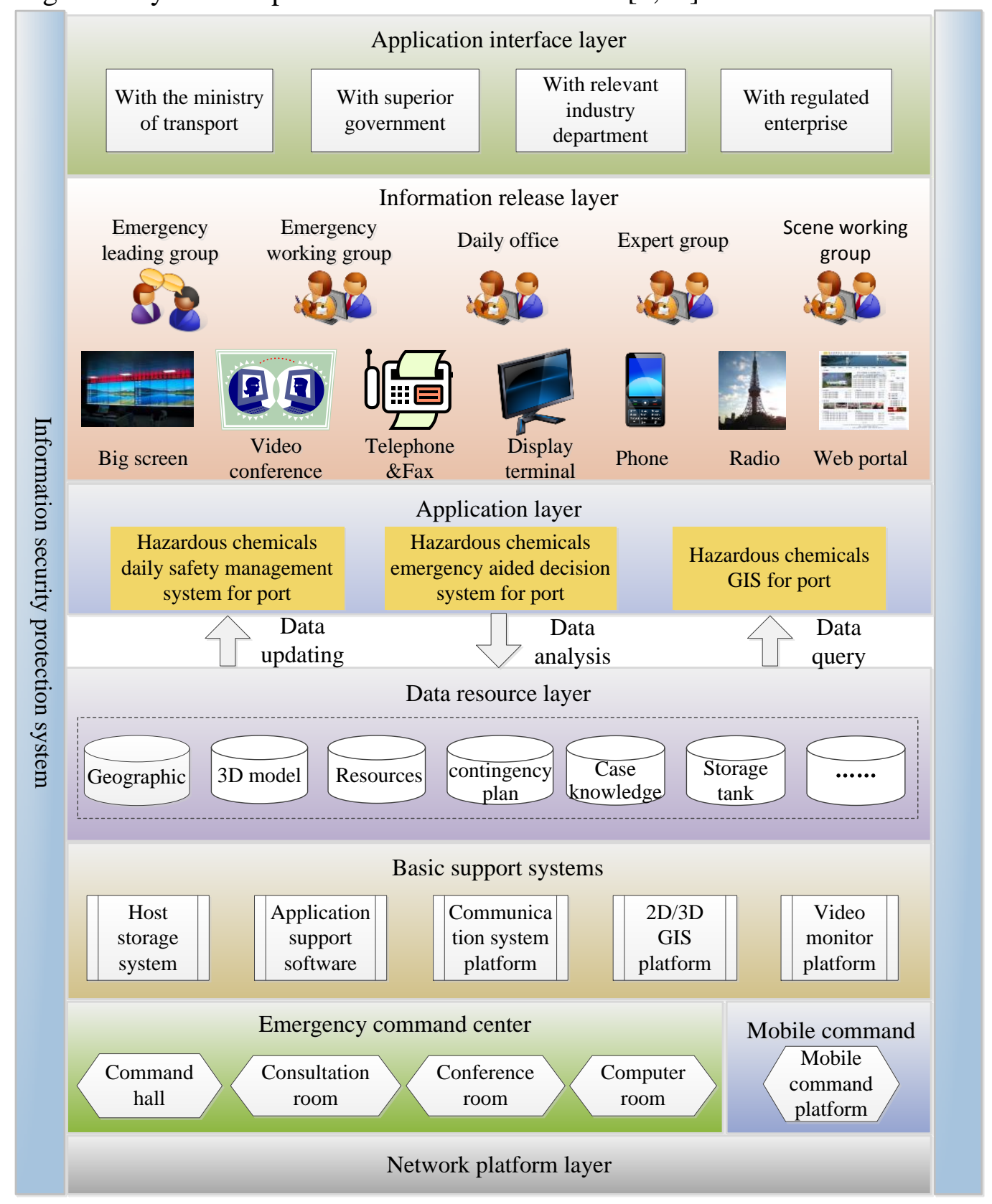

Fig.1 Overall architecture of hazardous chemicals safety supervision platform for port

Information release layer consists of the big screen, video conference system, display terminal, telephone, fax, phone, portals and other. Among them, the big screen, display terminal, telephone, fax, and mobile phones are mainly used for emergency operations management.

Application interface layer provides foundation data and communication mechanism for accessing and sharing upper and lower levels of emergency information resources, through unified information sharing interface. But also lay a solid foundation for the future data sharing with all types of external application from other industries (safety supervision, public security, fire protection, environmental protection, etc.). 


\section{Function Design of Platform Application System}

According to the framework of port hazardous chemicals safety supervision platform, the application layer building three application systems, respectively is hazardous chemicals geographic information system for port based on 3D visualization, hazardous chemicals emergency aided decision system for port based on the linkage of 2D and 3D, and hazardous chemicals daily safety management system for port based on Mobile Internet.

Hazardous Chemicals Geographic Information System for Port Based on 3D Visualization.

This system realizes the establishment of the fine GIS geographic information model for the entire port hazardous chemicals regulatory region and facilities, cover ground model, building model, such as peripheral auxiliary building, boiler room, sewage treatment plants, distribution, fire pump, nitrogen station, office building, garage fire etc., storage tank and pipeline modeling, installation details model, such as the important indoor or underground facilities, fire protection design, instrumentation, etc., port facilities and equipment model. So as to realize 3D visualization of tanks, chemical berth, pipelines and other important equipment, complete interactive browsing functions including zoom, rotation, translation for external environment, as well as public facilities and fire facilities.

\section{Hazardous Chemicals Emergency Aided Decision System for Port Based on the linkage of $2 D$ and 3D.}

This system realizes hazardous chemicals accidents disposal decision in port. Main functions include emergency duty management, emergency resource management, emergency decision making, emergency command and dispatch, emergency information dissemination, emergency assessment, accident case management and comprehensive statistical analysis. In addition, in order to reflect the combination of peacetime and wartime, users can carry out emergency drills and exercises throughout the computer simulation, realize hazardous chemicals accidents emergency simulation exercises by scenario planning and 3D geographic information system. Users can also formulate exercise plan, set drill, control and playback drill process, assess and record exercise effect.

Hazardous Chemicals Daily Safety Management System for Port Based on Mobile Internet.

This system makes full use of Mobile Internet technology to achieve daily safety supervision of port hazardous chemicals of business, which functions mainly include basic information management of port hazardous chemicals enterprise, examination and approval for operation of dangerous goods in port, certified management of personnel, record management of major hazard source in pore, accident investigation and risk management, such as self-examination and self-report and government supervision and inspection, record management of contingency plans, record management of safety evaluation agency, and comprehensive statistical analysis.

\section{Case Analysis}

According to the design ideas above, develop the hazardous chemicals safety supervision platform for Dalian pore. Hazardous chemicals in Dalian port are mainly distributed in Dagushan, Changxing Island and Songmu Island. As of 2014, there are 44 hazardous chemicals enterprise, 96 berths, 3 dangerous goods container station, 442 dangerous chemical storage tanks with a total capacity of 19.3 million cubic meters. Hazardous chemicals tank reserves accounted for about two-thirds of Dalian. This paper gives a brief introduction of hazardous chemical safety supervision platform for Dalian port.

3D Visualization and Efficient Display of Massive Multivariate Data.

This system, using independent research and development of 3D geographical information platform, can support data loading and model display and processing of massive 3D scene data, with the functions of grading loading and presentation skills. Besides, it can overlay display high resolution image information. A complete set of data 3D model data, high resolution image data, DEM data, amount up to 600G, can fluid load and roam in the system. By sharing with other GIS platform data, achieve homologous processing for data. 


\section{Seamless Integration of Video Surveillance Data and the $360^{\circ}$ Panorama.}

$360^{\circ}$ panorama technology actually is the use of panoramic camera, photographing on the surrounding environment by $360^{\circ}$ panoramic, and then synthesis processing constitute a panoramic view image, allowing the user fully understand the scene of the actual situation. Hazardous chemicals safety control scope in Dalian pore exists video monitoring point, cannot completely cover the area. Take the $360^{\circ}$ panorama as supplement, collecting and recording Major hazards and its surrounding environment, so as to understand scene situation in the process of emergency rescue.

\section{Show the Dynamic Pipeline Data by Classification Map and Section Profile.}

There are numerous kinds of pipeline in Dalian port, traditional maps show cannot intuitive understanding the material, diameter, media information of pipeline. Through classifying to the pipeline according their different medium, such as crude oil and refined oil, and make the profile on the important node in the intersection of the pipeline, which can solve the problems, and has been authorized in the practical application.

\section{Port Emergency Exercises with Established Plan and Random Trigger.}

System can simulate all kinds of unexpected situations through drill guide, can compare and analysis, and provide scene demonstration function for evaluation and teaching, in addition to achieve the traditional press to make a plan to carry out the exercise outside. In order to provide the perfect evaluation function, record and collect the whole process of exercise, and ready for playback. whole process of exercises and drills completely based on 3D scene model, exercise control steering the scene of 3D space, including control elements of equipment, people and accidents. So as to allow the exercise participants to be personally on the scene feeling, greatly enhance the exercise effect.

\section{Port Security Supervision by "Internet+".}

Hazardous chemicals supervision in port focuses on the daily work, daily safety hazards investigation and rectification is priority among priorities. Through the ideas of "Internet +", transfer the daily safety inspection work from the PC to mobile phone and other mobile devices. Through developing the corresponding safety supervision APP, inspection personnel can query port the enterprise security infrastructure information, download safety inspection record, record inspection results in the mobile terminal by intelligent terminal. At the same time, connect portable printer via Bluetooth, realize immediately print of inspection results. All information of the entire inspection process can be automatically synchronized to the server, facilitate to statistics and analysis for later.

\section{Conclusion}

Considering the actual needs of the current port hazardous chemicals safety supervision, effective integrate information technologies, such as 3D visualization, computer simulation, 2D and 3D geographic information, Mobile Internet, and port safety supervision business based on the combination of peacetime and wartime, to solve common problems existing in current port security supervision. And then design the port hazardous chemicals safety supervision platform, study overall framework, system function, core database, finally get application and examination in the dangerous chemical safety supervision platform for Dalian port.

The results shows that the platform can make daily safety management of hazardous chemicals, emergency decision-making and command into the system, collect information of safety supervision of hazardous chemicals, and analysis the port safety supervision and comprehensively on the basis of relevant information. Furthermore, provide decision for emergency aid of port hazardous chemicals emergency, and release emergency command through a variety of means of communication. It helps safety supervision departments be more scientific and reasonable, timely and accurately to take measures of disaster prevention, disaster relief and disaster reduction. So as to ensure the safety of Production operation personnel, reduce destroyed of production facilities in the disaster, improve the efficiency and accuracy of disaster evaluation, and finally improve the ability of port hazardous chemicals safety supervision industry. 


\section{References}

[1] Accident investigation report of special major fire explosion of Ruihai company dangerous goods warehouse in Tianjin port On August 12, 2016.

[2] ZENG Yamei, XU Liansheng. Status of Port's Dangerous Cargo Sites after Implement of New Rule[J], Science \& Technology of Ports, 2013,12.

[3] XU Liansheng, HU Yuchang and DUAN Xiaorui. The status and system of port major hazards of safety regulation [D], China Ports, 2010.03

[4] Pan Konggu. Research on Safety Management Mechanism of Dangerous Port Cargo - - A Case Study on Ningbo Port[D], Ningbo University,2012.

[5] ZHOU Zhaoxin. Study on mechanism of port large chemical storage area safety management regulation [J], Shanxi Youth,2013.22.

[6] HE Qiuping, WANG Yu. Research and application of major hazards safety regulation system for Nanjing port [J], China ITS Journal, 2011,S2.

[7] ZHOU zhaoxin. During the hazardous chemical materials safety in port from five aspects [N], China Marine newspaper,2014.9.

[8] GUAN Feng, LIU Hao and CAO Wei. Research on 2D and 3D linkage technology in disaster visual system [J], Science of Surveying and Mapping, 2012.03

[9] XU Liansheng, DUAN Xiaorui and HU Yuchang. Major hazards safety regulation system in regional port [J], Shipping Management, 2011.5.

[10] Information on http://www.mov.gov.cn. 